\title{
El símbolo como elemento unificador entre la teología y la poesía*
}

\author{
Luis Gustavo Meléndez Guerreroa \\ Universidad Iberoamericana, México \\ http://orcid.org/0000-0003-2988-6207
}

RECIBIDO: 10-10-19. APROBADO: 03-03-20

Resumen: Con este artículo esperamos establecer la relación entre teología y poesía basada en el poder de lo simbólico. Para abordar tal objetivo debemos considerar la siguiente pregunta: ¿De qué manera se puede alojar lo trascendente en lo inmanente? Creemos que es el carácter simbólico de la poesía lo que nos permite hablar de esta presencia de lo trascendente en lo inmanente. Para Paul Tillich, los símbolos se dirigen por encima de sí mismos hacia algo más. Los símbolos, a diferencia de los signos, participan en el poder de lo que simbolizan. Los símbolos religiosos pueden ser símbolos verdaderos solo si participan en el poder de lo divino al que apuntan. La revelación manifiesta nuestra preocupación última. En este sentido, la revelación de Jesús como el Cristo, en el que se arraiga el mensaje cristiano, es la revelación final y real, que a su vez resuelve la finitud de nuestra razón existencial. La importancia de los símbolos religiosos radica así en su "doble filo": apuntan a lo infinito, así como a lo finito; conducen lo infinito hacia lo finito y lo finito hacia lo infinito; revelan la vida divina para lo humano y lo humano para lo divino. Así entendido, el carácter simbólico será el vínculo que mueve el lenguaje poético hacia el lenguaje teológico cuando la tarea simbólica es, necesariamente, la que nos impulsa hacia un horizonte abierto, hacia el misterio que nos trasciende y al mismo tiempo que nos centra. A este fin, consultaremos con dos autores cuyo pensamiento orientará nuestra reflexión: desde un punto de vista teológico, Paul Tillich será nuestro principal punto de referencia; desde la dimensión poética, los escritos de Octavio Paz guiarán nuestra investigación. Mi hipótesis propone ver en la poesía un carácter mistagógico. Este concepto proporciona las bases para un diálogo entre la teología cristiana de la revelación (Tillich) y la idea de la "revelación poética" (como defiende Paz).

Palabras Clave: Símbolo; teología; poesía; carácter mistagógico; revelación; misterio; estética.

*Artículo de investigación.

a Autor de correspondencia. Correo electrónico: tavomg10@gmail.com 


\section{The Symbol as a Nexus between Theology and Poetry}

AвSTRACT: In this article we hope to establish the relationship between Theology and poetry based on the power of the symbolic. To approach such purpose, we will have to take into consideration the following question: How can the transcendent be lodged in the immanent? We believe that the symbolic character of poetry allows us to speak of this presence of the transcendent in the immanent. For Paul Tillich, symbols point out to something else above themselves. Unlike signs, symbols participate in the power of that which they symbolize. Religious symbols can be true symbols only if they participate in the power of the divine to which they point out. Revelation unveils our ultimate concern. Hence, the revelation of Jesus as the Christ, in which Christian message is rooted, is the final and actual revelation, which in turn resolves the finitude of our existential reason. Religious symbols are double-edged: they point out to the infinite as well as to the finite; they drive the infinite toward the finite and the finite toward the infinite; they unveil the divine life for the human and the human for the divine. Thus, the symbolic character will be the link that moves the poetic language towards the theological language when the symbolic task is, necessarily, that which propels us towards an open horizon, to the mystery that transcends us, and at the same time centers us. For this purpose, we will consult two authors whose thinking will orient our reflection: from a theological point of view, Paul Tillich will be our main reference; from the poetic dimension, the writings of Octavio Paz will guide our inquiry. My hypothesis proposes the possibility of emphasizing on the mystagogical character of poetry. This concept provides a dialogue between the Christian theology of revelation (Tillich) and the idea of "poetic revelation" (as defended by Paz).

Key Words: Symbol; Theology: Poetry; Mystagogical character; Revelation; Mystery; Aesthetics.

\section{Cómo CITAR:}

Meléndez Guerrero, Luis Gustavo. "El símbolo como elemento unificador entre la teología y la poesía”. Theologica Xaveriana (2021): 1-26. https://doi.org/10.11144/javeriana.tx71.seutp

\section{Reconocimiento}

Este trabajo se presenta como parte de la estancia de investigación posdoctoral en la Pontificia Universidad Católica de Paraná, en la ciudad de Curitiba, Brasil, dentro del sistema de Bolsa del Programa Nacional de Pós-Doutorado, PNPD, edital 07.2018. Fecha de inicio: diciembre de 2018; fecha de término: diciembre de 2019. 


\section{El problema de la revelación}

En aras de profundizar en el carácter simbólico como gozne entre lo poético y lo teológico queremos sentar a la mesa de este convivio al teólogo germano Paul Tillich, y así, orientados por su pensamiento introducirnos en el ámbito de la revelación de Dios, lo que en apariencia es menester exclusivo de la teología.

En el primer tomo de su Teología sistemática, Tillich establece que la revelación "es una manifestación especial y extraordinaria que levanta el velo de algo que está oculto de una manera especial y extraordinaria". En esta aproximación tillichiana, lo oculto es el misterio ${ }^{2}$, de modo que su postulado sobre la revelación de antemano nos advierte la presencia de una paradoja: mostrar algo que no deja nunca de mantener su enigma, algo que en sí mismo es irreductible a la mera razón, ya que trasciende el ámbito de la experiencia; al tiempo, lo que excede a la razón nos invita a ir más allá de ella, sin llegar por ello a ser irracional: “...el verdadero misterio aparece cuando la razón se ve conducida, más allá de sí misma, a su 'fondo y abismo', a lo que 'precede' a la razón [...] al hecho original (Urtatsache) de que hay algo y no nada”3.

Tal experiencia mueve a la razón a pasar más allá de sí misma y deja al descubierto nuestra finitud, algo que es propio de nuestra condición humana. Tillich la llama "la faz negativa del misterio" 4

Ahora bien, a la vez que se experimenta la limitación que constituye nuestro ser sujetos, "algo" se manifiesta como trascendente y, sin importar nuestra pequeñez, nos asombra eso que nos rebasa y a la vez nos seduce y conduce hacia un fondo que es también fundamento. A esta realidad del misterio que es fondo y sustento Tillich la llama la "faz positiva del misterio". Desde esta faceta positiva, "el misterio se presenta

${ }^{1}$ Tillich, Teología sistemática. Vol. I: La razón y la revelación. El ser y Dios, 146.

${ }^{2} \mathrm{Al}$ hablar de misterio, Paul Tillich está considerando el sentido etimológico del término: "Misterio [...] procede de muein, 'cerrar los ojos' o 'cerrar la boca'. Para alcanzar un conocimiento ordinario, es necesario abrir los ojos a fin de aprehender el objeto y abrir la boca a fin de comunicarse con otras personas y poner a prueba las propias intuiciones. En cambio, la experiencia de un verdadero misterio se cumple en una actitud que contradice la actitud requerida por el conocimiento ordinario. Los ojos están 'cerrados' porque el verdadero misterio trasciende el acto de ver, de confrontar objetos cuyas estructuras y relaciones se presentan a un sujeto para que las conozca. El misterio caracteriza una relación que precede a la relación sujeto-objeto y está vinculado a él [...] Todo lo que es esencialmente misterioso no puede perder su carácter de misterio, ni siquiera cuando es revelado [...] esta aparente paradoja [revelar y, al mismo tiempo mantener oculto parte del misterio] es precisamente la que afirman la religión y teología" (Tillich, Teología sistemática. Vol. I: La razón y la revelación. El ser y Dios, 146).

${ }^{3}$ Ibíd., 147.

${ }^{4}$ Ibíd., 147. 
como el fondo, y no únicamente como el abismo del ser. Se presenta como el poder de ser, que conquista al no ser. Se presenta como nuestra preocupación última”.

Para Tillich, la manifestación bifásica del misterio solo es susceptible de expresarse por medio de símbolos y mitos. Si la revelación se entiende como el acto en el cual viene a nosotros eso que nos ocupa o concierne incondicionalmente, es necesario explicitar los medios por los cuales la revelación acontece. Para ello Tillich señala tres medios de revelación, a saber: la naturaleza; la historia y personas; y la palabra. Expondremos brevemente los dos primeros, y centraremos luego nuestra atención en el tercero.

Tillich señala que "no existe realidad, cosa o acontecimiento alguno que no pueda ser portador del misterio del ser y entrar en una correlación reveladora”, ${ }^{6}$, pero se apresura a señalar que ni la naturaleza ni la historia, como tampoco las personas, en sí mismas, pueden conducirnos a la revelación del fondo del ser. Al respecto, comenta: “...ni persona ni cosa alguna es digna en sí misma de representar nuestra preocupación última”’

Con esto, el autor germano quiere decir que la revelación no se posibilita gracias a las cualidades que pudiesen estar presentes en los entes ni en la historia; personas, eventos o cosas no son -en sí mismos- portadores de la revelación, y mucho menos son la revelación; antes bien, "estas cualidades determinan la dirección en la que una cosa o un acontecimiento expresa nuestra preocupación última y nuestra relación con el misterio del ser"s.

Tillich plantea esta aclaración para retomar la idea de que el contenido de la revelación nos concierne, ya que alberga el misterio de lo divino, el cual nos devela su carácter abisal. ¿Cuál es entonces el papel de dichos medios de revelación? La naturaleza, en todo caso, sugiere los vestigios de lo que nos concierne últimamente; sin embargo, la naturaleza no puede ser la base de la revelación en cuanto tal. Algo parecido ocurre con las personas y los eventos históricos. A decir de Tillich, en sí mismos estos "no son medios de revelación"; antes bien, son "la constelación reveladora en la que entran bajo unas condiciones particulares la que los hace reveladores".

Lo que Tillich plantea no es la negación de una revelación que ocurre por medio de personas y hechos históricos; más aún, ya desde las Lecciones de Dresde

\footnotetext{
${ }^{5}$ Ibíd., 148.

${ }^{6}$ Ibíd., 157.

${ }^{7}$ Ibíd., 158.

${ }^{8}$ Ibíd.

${ }^{9}$ Ibíd., 161.
} 
1925-192710, él señalaba la necesidad de hablar de una revelación histórica. El problema estriba, no en negar sin más la mediación de personas o hechos concretos, como en resaltar que no es en ellos sino por medio de ellos que la revelación puede ocurrir.

Más todavía, Tillich enfatiza en que el papel mediador de tales realidades (historia y personas) radica en la necesidad de ser experimentados extáticamente, esto es, que al trascenderse a sí mismos nos lleven más allá de lo que evidencian. Así entendidos, tanto los acontecimientos históricos como las personas "apuntan hacia algo que los trasciende infinitamente, hacia la automanifestación de lo que nos preocupa últimamente" ${ }^{11}$.

Llegamos así al punto en el cual centraremos nuestra reflexión en este apartado: nos referimos a la palabra como medio por el cual el ser humano puede expresarse. En relación con la mediación de la palabra, Tillich advierte la necesidad de su primacía respecto de los otros medios de la revelación mencionados, toda vez que, sin la presencia de la palabra resultaría imposible comprender la revelación, ya que en su centro habita el Logos divino. En lo que atañe a nuestra condición humana, el lenguaje es el medio por antonomasia por el cual nos proyectamos en cuanto seres de palabra ${ }^{12}$.

Ahora bien, hay que distinguir entre la palabra humana que media el dato revelado y la Palabra divina. Tillich considera que las palabras humanas están contextualizadas, surgen al interior de la historia concreta, al tiempo que pretenden establecer una correlación entre la mente y la realidad. En cambio, la Palabra divina es en sí misma un fondo que fundamenta y no necesita mayor contexto ni adecuación para validar su verdad. Con todo, Paul Tillich enfatiza en la relevancia de la palabra humana como medio para comunicar (verbalizar, transmitir, expresar) la revelación del Logos divino.

Ahora bien, al ser consecuente con su propuesta teológica, Tillich señala que -dada la trascendencia radical del objeto de nuestra preocupación última- el lenguaje humano per se es insuficiente para decir la realidad de la que nos habla la revelación; por ende, todo lo que se diga de la revelación deberá hacerse en sentido simbólico. Por ello, el poder expresivo del lenguaje facilita la posibilidad de comunicar algo de la revelación. Al respecto, señala Tillich:

...la palabra como medio de revelación apunta hacia más allá de su sentido ordinario tanto en la denotación como en la expresión. En la situación de revelación, el lenguaje posee un poder denotativo que, a través de la significación ordinaria de las palabras, apunta a la relación que estas tienen con nosotros. En la situación de revelación, el lenguaje posee un poder expresivo que, a través de

\footnotetext{
${ }^{10} \mathrm{Al}$ respecto, véase la obra de Tillich, Dogmática (Lecciones de Dresde 1925-1927).

${ }^{11}$ Tillich, Teología sistemática. Vol. I: La razón y la revelación. El ser y Dios, 162.

${ }^{12} \mathrm{Al}$ respecto véase a Fries, Teología fundamental.
} 
las posibilidades de expresión ordinarias del lenguaje, apunta a lo inexpresable y a la relación que este tiene con nosotros. Esto no significa que la estructura lógica del lenguaje ordinario quede destruida cuando la palabra se convierte en un medio de revelación. ${ }^{13}$

Esta capacidad metafórica (expresiva) del lenguaje señalada por Tillich es lo que una y otra vez reitera Octavio Paz a lo largo de su obra ensayística. Baste aquí citar unas breves pero sustanciosas palabras de su relevante obra El arco y la lira: “...el lenguaje, en su realidad última, se nos escapa" ${ }^{14}$. Ante el sentido diferido de lo otro que nos seduce y provoca vértigo, el poder metafórico de la poesía nos ayuda a nombrar aquella realidad: “...la palabra es un puente mediante el cual el hombre trata de salvar la distancia que lo separa de la realidad exterior [ya que la palabra poética dice] 'esto y lo otro' y, al mismo tiempo, aquello y lo de más allá" ${ }^{15}$. En otra de sus obras, Paz se refiere a este potencial de sentido a partir de la analogía: “...la analogía es la ciencia de las correspondencias [aunque esta] no vive sino gracias a las diferencias: precisamente porque esto no es aquello, es posible tender un puente entre esto y aquello [...] esto es como aquello, esto es aquello"16.

Tillich, por su parte, en el primer volumen de Teología sistemática, resalta la pertinencia de la analogía al momento de hablar de la revelación. Él se remite así a la tradición de la analogia entis para hablar de la relación entre lo finito y lo trascendente: "Sin esa analogía nada se podría decir acerca de Dios. Pero la analogia entis [...] no es un método para descubrir la verdad sobre Dios; es la forma en la que debe expresarse todo conocimiento de revelación" ${ }^{17}$.

Podemos colegir que algo extraordinario resplandece a través de lo ordinario, y ese algo es, precisamente, lo que da sentido y fundamento al hombre. Gracias al sentido abierto del lenguaje, la palabra falible del hombre tiene la posibilidad de servir como medio propicio para expresar la presencia del misterio que se manifiesta a través de lo finito y condicionado, ya que "cuando se habla de lo último del ser y de la significación, el lenguaje corriente lo retrotrae al nivel de lo previo, de lo condicionado, de lo finito" ${ }^{18}$.

\footnotetext{
${ }^{13}$ Tillich, Teología sistemática. Vol. I: La razón y la revelación. El ser y Dios, 165.

${ }^{14} \mathrm{Paz}$, El arco y la lira, 31.

${ }^{15}$ Ibíd., 36; 49.

${ }^{16}$ Paz, Los hijos del limo, 109 (cursivas del autor).

${ }^{17}$ Tillich, Teología sistemática. Vol. I: La razón y la revelación. El ser y Dios, 174.

${ }^{18}$ Ibíd., 165.
} 
En este sentido, el teólogo protestante puede decir que el lenguaje humano, en cuanto medio para la revelación, "posee el 'sonido' y la 'voz' del misterio divino"; el lenguaje ordinario se torna el vehículo por medio del cual "algo resplandece (o con más exactitud, algo suena) y este algo es la automanifestación de la profundidad del ser y del sentido" ${ }^{19}$.

Se ha dicho que únicamente por una vía indirecta y gracias al carácter metafórico del lenguaje la palabra humana está en posibilidades de servir como medio de revelación. ¿A qué se refiere Tillich cuando habla de una vía indirecta? En las Lecciones de Dresde dejó en claro que, al hablar de la revelación, debemos considerar un acto en el cual viene a nosotros eso que nos concierne incondicionalmente, y añadió que lo incondicionado es indecible, por lo cual habrá que considerar que lo que se revela escapa a cualquier pretensión de encorsetamiento por parte del lenguaje.

Por tanto, hay que señalar que la revelación no es directa sino mediada, indirecta. Al señalar que la revelación es indirecta, Tillich considera que lo que se revela es el misterio (muein) y, como tal, este se presenta como indecible, algo que trasciende nuestra posibilidad de ver y decir. La realidad incondicionada es lo oculto por excelencia, ya que cuando hablamos del misterio divino hablamos del misterio del ser en sí, de modo que incluso al decir que Dios se revela habrá que considerar que lo que se revela lo hace sin dejar de ser misterio ${ }^{20}$.

Al señalar que el misterio revelado se manifiesta sin dejar de ser misterio no debemos identificar el misterio con una carencia de sentido, "sino con un trascender del sentido" ${ }^{21}$. Podemos colegir que la manifestación del misterio solo es susceptible de expresarse simbólicamente: es decir, que el símbolo es el modo como acontece la revelación, que esta se conduce por medio de la dinámica del símbolo. Pero ¿qué es un símbolo?

\footnotetext{
${ }^{19}$ Ibíd., 165-166. En este marco del lenguaje nos resulta imposible dejar de lado las palabras del Nobel de Literatura, Octavio Paz, ideas tan cercanas aquí al sentir de Tillich: “...el poema -boca que habla y oreja que oye- será la revelación de aquello que la exclamación señala sin nombrar” (Paz, El arco y la lira, 47). Con ello, parece que don Octavio expresa la misma realidad mencionada por Tillich. La palabra poética se presta para ser la voz de eso que está más allá, de eso que no podemos decir y que, sin embargo, expresamos poéticamente. He aquí la importancia de la palabra como elemento primordial en la revelación.

${ }^{20}$ Tillich, Teología sistemática. Vol. I: La razón y la revelación. El ser y Dios, especialmente 145-149.

${ }^{21}$ Tillich, Dogmática (Lecciones de Dresde 1925-1927), 60.
} 


\section{El poder del símbolo religioso}

En un artículo de 1955 publicado en la revista The Christian Scholar22, Tillich señala lo que considera son los rasgos característicos de los símbolos, a saber: (1) que apuntan más allá de sí mismos ("they point beyond themselves"); (2) que a diferencia del signo participan del poder de eso que están simbolizando ("the participation in the symbolized reality"); (3) que nos permiten la apertura a un nivel de sentido al que de otro modo nos sería imposible acceder ("every symbol opens up a level of reality") ${ }^{23}$.

El primero de tales aspectos está de alguna manera explicitado en la etimología misma del símbolo (arrojar o lanzar con). Por ello, Tillich enfatiza un poco más en el segundo de los rasgos señalados, y considera que en principio si bien es cierto que tanto el signo como el símbolo señalan una realidad fuera de sí mismos, símbolos y signos difieren de manera sustancial en que estos últimos no participan del poder al cual apuntalan, mientras que los símbolos sí lo hacen:

Signs do not participate in any way in the reality and power of that to which they point. Symbols, although they are not the same as that which they symbolize, participate in its meaning and power. The difference between symbol and sign is the participation in the symbolized reality, which characterizes the symbols, and the non-participation in the "pointed-to" reality which characterizes a sign. ${ }^{24}$

El punto clave para el teólogo germano -como podemos ver- es la idea de la participación. Él señala que hay ciertos tipos de lenguaje que nunca pasan de ser meras referencias de algo (los signos matemáticos, las señales de tránsito), pero que existen otros lenguajes -el poético o el litúrgico- que apuntalan hacia algo exterior a sí mismos, al tiempo que participan del poder de aquello a lo que refieren: “...they have become not only signs pointing to a meaning which is defined, but also symbols standing for a reality in the power of which they participate" 25 .

\footnotetext{
${ }^{22}$ Véase a Tillich, "Religious Symbols and our Knowledge of God".

${ }^{23}$ Un profundo análisis sobre el sentido de los símbolos religiosos (salvación, redención, justificación, salvador, mediador, mesías, etc.) desde una perspectiva existencialista, puede verse en Tillich, Main Works 6: Theological Writings, el texto "Existential Analyses and Religious Symbols", 385-399.
}

${ }^{24}$ Tillich, "Religious Symbols and our Knowledge of God”, 189-190. "Los signos no participan de ninguna manera en la realidad y el poder de aquello a lo que apuntan. Los símbolos, aunque no son lo mismo que simbolizan, participan en su significado y poder. La diferencia entre símbolo y signo es la participación en la realidad simbolizada, que caracteriza a los símbolos, y la no participación en la realidad 'señalada' es lo que caracteriza a un signo" (la traducción es nuestra).

${ }^{25}$ Ibíd., 190. "Ellos [los signos] se han convertido no solo en signos que apuntan a un significado definido, sino también en símbolos que representan una realidad en el poder del cual participan" (la traducción es nuestra). 
Sin más preámbulo, vayamos ahora al tercero de los rasgos del símbolo enlistados arriba. Hemos dicho que-según Tillich-el símbolo nos permite la apertura a un nivel de sentido al que de otro modo nos estaría negado acceder; y esta es la función clave de los símbolos: "...to point beyond themselves in the power of that to which they point, to open up levels of reality which otherwise are closed, and to open up levels of the human mind of which we otherwise are not aware" ${ }^{26}$.

En el contexto simbólico que menciona Tillich, su objeto principal es advertir el carácter distinto del símbolo respecto del signo, enfatizando así en el hecho de que el símbolo participa del poder de aquello a lo que nos lanza.

As a symbol it participates in the power of the ultimate to which it points $[\ldots]$ it participates in the "holy". "Holy" and "sacred" point to the presence of the ultimate power of being and of meaning in an individual thing or situation [...] This participation, which, on the one hand, is the reason for the greatness and holiness of the symbol, and, on the other hand, accounts for its smallness and limitation, must be understood in reference to every religious symbol. ${ }^{27}$

Tillich muestra interés por enfatizar en la idea de la participación que el símbolo tiene con el poder de aquello a lo que hace referencia. Este distintivo le ayuda a profundizar en los elementos propios del símbolo religioso; sin embargo, deja en claro que participación no significa identidad, es decir, que los símbolos nos hacen participar de lo divino pero sin llegar a generarse un traslape entre lo divino y lo inmanente.

Al mencionar los rasgos distintivos de la vida del símbolo, Tillich enfoca su reflexión sobre un tipo en particular: los símbolos religiosos. Si uno de los rasgos fundamentales del símbolo es el hecho de su apertura a la realidad, de manera especial el símbolo religioso nos lanza, no a la realidad sin más sino a la realidad última, al fundamento de la realidad, esto es, a la dimensión de lo sagrado. Tales símbolos religiosos tienen a su vez dos ámbitos en los que la vida simbólica se desenvuelve: lo trascendente y lo inmanente ${ }^{28}$.

${ }^{26}$ Tillich, "Theology and Symbolism”, 109. "Para señalar más allá de sí mismos en el poder de aquello a lo que apuntan, para abrir niveles de realidad que de otro modo estarían cerrados, y para abrir niveles de la mente humana de los que de otra manera no somos conscientes" (ibíd.; la traducción es nuestra).

${ }^{27}$ Ibíd., 110-111. "Como símbolo, participa en el poder de aquella ultimidad a la cual señala [...] participa en lo 'santo'. Lo 'santo' y lo 'sagrado' apuntan a la presencia del poder supremo del ser y del significado en una cosa o situación individual [...] Esta participación, que, por un lado, es la razón de la grandeza y santidad del símbolo y, por otro lado, explica su pequeñez y limitación, debe entenderse en referencia a cada símbolo religioso" (ibíd.; la traducción es nuestra). Esta misma idea de la participación será abordada con mayor extensión en su Teología sistemática. Vol. I: La razón y la revelación. El ser y Dios.

${ }^{28}$ Aquí conviene hacer una pequeña acotación que aclare la distinción trascendente-inmanente elaborada por el mismo autor. En el citado artículo de 1955, "Religious Symbols and our Knowledge of God", 
En el nivel trascendente de lo simbólico se explica que Dios, en sí mismo, no puede ser un símbolo. Al acudir a la tradición escolástica, Tillich señala que Dios es el esse ipsum, el ser en $s^{29}$, y como tal escapa a toda forma de conceptualización y objetivación. Sin embargo, si pretendemos decir algo sobre Dios y si pretendemos relacionarnos con él es necesario referirnos a Dios simbólicamente.

En este mismo nivel trascendente, Tillich habla de un segundo elemento o rasgo distintivo: los atributos divinos. Estos son meras formas o modos de hablar humano que surgen a partir de nuestras propias cualidades que atribuimos a Dios de modo eminente; no obstante, el aspecto simbólico de dicho hablar es necesario para poder referirnos a lo divino.

Finalmente, el teólogo germano menciona un tercer elemento en la dimensión trascendente, a saber, el orden temporal. Cuando decimos que Dios ha creado el mundo o que Dios ha enviado a su Hijo al mundo ${ }^{30}$, hacemos referencia a una serie de intervenciones divinas en el orden temporal; pero si Dios es el ser en sí, necesariamente está fuera de nuestras categorías espacio-temporales; Dios está más allá de nuestra categoría "tiempo", y por tanto, si hablamos de Dios en términos de temporalidad, lo hacemos simbólicamente.

Tillich hace la distinción entre un ámbito trascendente y otro inmanente en los símbolos religiosos, y a su vez, cada ámbito se subdivide en tres rasgos distintivos. Sin embargo, en el texto de 1969, "Theology and Symbolism", Tillich no distingue entre lo trascendente y lo inmanente como ámbitos o niveles del símbolo religioso; esta vez sintetiza lo propuesto en el artículo de 1955, para hablar de modo más genérico de tres niveles de los símbolos religiosos, a saber: trascendental, sacramental y litúrgico. Al parecer, el proceder sintético de Tillich hace pensar en una necesidad de entender que, en la vida del símbolo religioso, lo inmanente y lo trascendente están fuertemente co-implicados, sin que ello signifique que se pierda la distancia entre lo inmanente y lo trascendente. Nosotros hemos optado por la división que utiliza Tillich en el texto de 1955, para marcar un poco más, tanto la relación como la distancia entre lo inmanente y lo trascendente que existe en la vida del símbolo.

${ }^{29}$ Sobre el problema de considerar a Dios desde la categoría del "ser", Tillich señala que semejante pretensión representa un gran problema para la teología. El problema radica en que queremos aprisionar a Dios en la esfera del ser, cuando en realidad, Dios está más allá del ser: “...no puede entenderse el ser de Dios como la existencia de un ser junto a otros seres por encima de ellos. Si Dios es un ser, está sujeto a las categorías de finitud [...] Podrían evitarse muchas confusiones en la doctrina de Dios y muchas endebleces apologéticas, si ante todo se concibiera a Dios como el ser en sí o como el fondo del ser [Dios] es el poder de ser en todo [...] Dios está más allá de la oposición entre ser esencial y el ser existencial [...] Dios está más allá de la esencia y de la existencia [...] Dios es el ser en sí, no un ser” (Tillich, Teología sistemática. Vol. I: La razón y la revelación. El ser y Dios, 303-304; 305).

${ }^{30}$ Dice el autor: "In one small sentence: 'God has sent his son'. Here we have in the Word 'has' temporality. But God is beyond our temporality" (Tillich, "Theology and Symbolism”, 194). "En una pequeña oración: 'Dios ha enviado a su hijo'. Aquí, en la palabra 'ha [enviado]', tenemos temporalidad. Pero Dios está más allá de nuestra temporalidad” (ibíd. La traducción es nuestra). 
La segunda dimensión del símbolo religioso vislumbrado por Tillich es lo inmanente: este es el espacio donde acontecen las manifestaciones de lo divino, es decir, el ámbito de lo espacio-temporal. Aquí el autor señala, grosso modo, tres elementos o rasgos distintivos de lo inmanente, a saber: las encarnaciones, lo sacramental y lo que él llama signos-símbolo:

- Sobre el primero de los elementos (encarnaciones), el plural obedece a que Tillich no centra su atención en el misterio de la encarnación propia del cristianismo; antes bien considera aquí las distintas formas como diferentes tradiciones religiosas han presentado la idea de la encarnación como medio esencial por el cual la divinidad se aproxima -por medio de la corporalidada nuestra realidad humana ${ }^{31}$.

- El segundo elemento o rasgo distintivo del ámbito de lo inmanente es el sacramental. Su importancia radica en el hecho de que algo que forma parte de nuestra realidad cotidiana puede ser portador de lo sagrado. Tillich menciona aquí el sacramento por excelencia del rito católico, la eucaristía, en la cual los elementos materiales del pan y el vino, sin dejar de ser lo que son, son algo más: cuerpo y sangre de Cristo ${ }^{32}$.

- Llegamos así a los signos-símbolo, el tercer elemento propio del ámbito inmanente de los símbolos religiosos. A nuestro parecer, este rasgo está en íntima relación con el anterior (sacramento); quizás el hecho de mencionarlo como elemento aparte obedece a la intención de enfatizar en la primacía sacramental que tiene la eucaristía respecto de otros elementos materiales como el agua, el fuego o el aceite, cuyo valor simbólico también es sumamente importante en distintos ritos de culto cristianos, así como su papel en los ritos sacramentales de iniciación. En este tercer elemento existen otras realidades materiales como los edificios y algunos objetos (la cruz) que forman parte importante de la

\footnotetext{
${ }^{31} \mathrm{Al}$ respecto dice Tillich: “...the divine begins always incarnate in different forms [...] The more transcendent the gods become, the more incarnations of personal or sacramental character are needed in order to overcome the remoteness of the divine which develops with the strengthening of the transcendent element" (Tillich, "Theology and Symbolism", 195). "Lo divino comienza siempre encarnado en diferentes formas [...] Cuanto más trascendentes se vuelven los dioses, más encarnaciones de carácter personal o sacramental son necesarias para superar la lejanía de lo divino que se desarrolla con el fortalecimiento del elemento trascendente" (la traducción es nuestra).

${ }^{32}$ Dice el autor: “. ...in the real sense of symbol, the sacramental materials are symbols. But if the symbol is used as only symbol [...], then of course the sacramental materials are more than this". "En el sentido real del símbolo, la materia sacramental es símbolo. Pero si el símbolo se usa como único símbolo [...], entonces, por supuesto, los materiales sacramentales son más que esto” (la traducción es nuestra) (ibíd., 195; énfasis del autor).
} 
dinámica cultual de los cristianos. Tales elementos -que en apariencia podrían ser meramente signos- adquieren valor especial (lo cual, en la clasificación que ha hecho el autor, al ser únicamente signos, aun y cuando apuntalaran a una realidad superior, solo como signos no podrían participar del poder de la realidad a la cual refieren). Es gracias a esa suerte de valor agregado que los signos no son solo eso, sino algo más: son símbolos. Tillich opta por llamarles signos-símbolo: "I call them sign-symbols, signs which have become symbols"33.

La propuesta de Tillich aquí revisada nos plantea, grosso modo, la forma en que el símbolo religioso se presenta como el modo propicio para hablar de lo que en sí mismo es inefable. Por ello, según Tillich, si la teología pretende hablar de la revelación de Dios debe hacerlo mediante el lenguaje simbólico. Aquí radica nuestro interés por explicitar el carácter mediador de lo simbólico en la revelación.

Si la revelación de la que nos da cuenta la teología es potencializada mediante la dinámica del símbolo, quizás podamos resaltar también una riqueza mediadora por parte de la poesía, en aras de aportar, por medio de la riqueza del imaginario poético, una vía de mediación que posibilite aproximarnos a la experiencia de lo que acontece en la revelación cristiana. En este sentido, igual que la revelación teológica expresada por medio del lenguaje simbólico, la revelación poética apuntala a un horizonte siempre nuevo.

$\mathrm{Si}$-como hemos visto de la mano de Tillich- historia, mundo y palabra son medios por los cuales acontece la revelación, y entre dichos medios, la palabra es la que cobra el papel protagónico entre las formas de revelación, bien podemos afirmar que la palabra poética puede presentarse como medio mistagógico privilegiado mediante el cual la presencia de lo divino se nos manifiesta.

\section{La revelación poética}

En aras a profundizar en el sentido de la revelación poética es tiempo de invitar a la mesa de este convite del pensamiento al poeta y Premio Nobel de Literatura Octavio Paz. En su obra, el término revelación no se presenta bajo la forma de un concepto preciso; creemos que, a pesar de su carácter polifacético en cuanto al sentido al que alude, podemos decir que se trata de una referencia a la presencia que se manifiesta, causando fascinación, atracción y temor con su esplendor. En El arco y la lira, más que una definición, Paz nos proporciona una descripción de la revelación, de lo que acontece insospechadamente:

33 "Religious Symbols and Our Knowledge of God", 196. 
A veces, sin causa aparente [...] vemos de verdad lo que nos rodea. Y esa visión es, a su manera, una suerte de teofanía o aparición pues el mundo se nos revela en sus pliegues y abismos [...] todos los días cruzamos la misma calle o el mismo jardín; todas las tardes nuestros ojos tropiezan con el mismo muro rojizo [...] de pronto, un día cualquiera, la calle da a otro mundo, el jardín acaba de nacer, el muro fatigado se cubre de signos. Nunca lo habíamos visto y ahora nos asombra que sean así. ${ }^{34}$

Como la rosa de Angelus Silesius que deja ver la paradoja del "sin por qué" ("la rosa es sin por qué/ florece porque florece") ${ }^{35}$, la revelación poética también es sin por qué. Dejemos que el poeta mexicano extienda su descripción. En una entrevista recogida por Alberto Ruy Sánchez, Paz se refirió a la revelación en los siguientes términos:

Creo que todos los hombres, todos los niños, algunas veces los enamorados, todos nosotros cuando nos quedamos viendo un crepúsculo, o viendo un cuadro, o viendo un árbol, o viendo nada, viendo una pared simplemente, vivimos esos momentos en los que el tiempo se anula, se disuelve: los grandes momentos del hombre son su salida. Es lo que llamo nuestra pequeña ración de eternidad. No sé si tengamos otra pero esta sí la tenemos y es algo que la poesía proclama. Si la gente leyese más poesía en este siglo podría quizás acceder más fácilmente a esos instantes. No porque la poesía los cree sino porque la poesía los revela. ${ }^{36}$

La revelación poética se presenta como una manifestación que logra aprisionar, en el instante poético, los eventos, cosas o personas mediante los cuales la realidad se nos transfigura, haciéndonos gozar - por breves momentos- de la experiencia de lo eterno. Estas epifanías acaso sean también apariciones que provocan -entre otras cosas- que el tiempo se abra para hacer sitio a la presencia.

Apariciones,

el tiempo se abre:

La poesía no es la verdad:

es la resurrección de las presencias. ${ }^{37}$

¿Qué presencia es esa que acontece en la revelación poética? Más aún, ¿qué nos dice dicha revelación? Quizás sea conveniente señalar que lo que se manifiesta nos dice; revela nuestra frágil naturaleza, pero también la posibilidad de ser lo que somos: plenitud. Eventos, cosas y personas son los medios por los cuales el esplendor

\footnotetext{
${ }^{34} \mathrm{Paz}$, El arco y la lira, 133.

${ }^{35}$ Véase a Angelus Silesius, El peregrino querúbico.

${ }^{36}$ Ruy Sánchez, Una introducción a Octavio Paz, 118.

${ }^{37}$ Paz, en Obras completas VII: Obra poética, 667; 672: "Nocturno de San Ildefonso".
} 
de la gloria se nos manifiesta transfigurando la realidad y mostrando el reverso de la palabra, el reverso del ser, lo Otro.

La poesía es búsqueda de sentido: uno que rebasa la mera significación y que se proyecta más allá del significado. Al tiempo, la pregunta por el sentido es también pregunta por la otredad; la pregunta se plantea como búsqueda y, todavía más, como acto de fe. Según Paz, lo que se presenta en la revelación poética es un don que acontece de modo insospechado.

En una de sus obras capitales, El arco y la lira, Octavio Paz resalta precisamente el valor simbólico de la poesía al decir que "la esencia del lenguaje es simbólica porque consiste en presentar un elemento de la realidad por otro"38. A nuestro parecer, el valor simbólico de la poesía coincide también con el simbolismo religioso del que hacíamos mención siguiendo a Paul Tillich, toda vez que -igual que el símbolo religioso- la poesía nos permite otear un horizonte más vasto. Así también -como plantea Tillich- por la vía de la participación, el lenguaje poético nos arroja al misterio; no en vano señalaba Paz que "todo nos lleva a insertar el acto poético en la zona de lo sagrado" ${ }^{39}$.

Sin embargo, ¿qué es esta realidad sagrada de la que da cuenta el Nobel mexicano? Si bien es cierto que Paz se consideraba a sí mismo agnóstico, nunca dejó de afirmar la importancia de lo religioso en la vida del hombre. Sin apegarse a una confesión religiosa en particular, pero bebiendo de distintas tradiciones como el cristianismo, el hinduismo y el budismo, se refirió - una y otra vez- en sus textos, a lo sagrado.

De manera especial el mexicano parece comprender lo sagrado como un ámbito en el cual acontece una revelación, una experiencia del misterio que nos causa extrańeza, nos seduce e invita al arrojo y, una vez seducidos y lanzados -mediante un salto mortal- somos conducidos a la otra orilla. En palabras de Paz: ...la poesía pone al hombre fuera de sí y, simultáneamente lo hace regresar a su ser original: lo vuelve a sí [...] A través de la frase que es ritmo, que es imagen, el hombre -ese perpetuo llegar a ser- es. La poesía es entrar en el ser” ${ }^{\prime \prime}$.

A nuestro parecer, es posible ver aquí cercanía en la función simbólica que opera tanto en lo teológico como en lo poético. La cualidad simbólica de la palabra poética, lo mismo que el valor del símbolo religioso, provoca la apertura de nuevos horizontes de sentido, nos arroja a ellos, a un hontanar siempre nuevo, y nos hace participar de lo que se manifiesta en el seno mismo de ese fondo al que hemos sido arrojados. En

\footnotetext{
${ }^{38} \mathrm{Paz}$, El arco y la lira, 34.

${ }^{39}$ Ibíd., 117.

${ }^{40}$ Ibíd., 113.
} 
este sentido, la poesía ha de ser considerada como la experiencia de la palabra que nos ayuda a verbalizar una experiencia más grande todavía: la experiencia de la otredad, del misterio que nos concierne en ultimidad.

En el caso de Octavio Paz, la íntima relación entre religión y poesía es un hecho que el poeta defiende en distintos lugares de sus ensayos: dice que ambas tienden a realizar la posibilidad de ser que somos (ser yo, pero también ser otro), y por ello, tanto la poesía como la religión "son tentativas por abrazar esa otredad que Machado llamaba 'la esencial heterogeneidad del ser"” ${ }^{41}$.

Paz entiende que dicha heterogeneidad del otro provoca un movimiento que nos lleva a su encuentro, y de ahí que mencione -siguiendo a Kierkegaard- la idea del salto para expresar la imagen del arrojo que implica la experiencia del encuentro con la otredad. "La experiencia poética como la religiosa es un salto mortal: cambiar de naturaleza que es también regresar a nuestra naturaleza original”“2.

El poeta mexicano utiliza una palabra propia del vocabulario teológico, aunque no exclusivo de este ${ }^{43}$; habla de una revelación que no es necesariamente exclusiva en la religión y puede ser utilizada para hablar de la poesía ya que, para él, "poesía y religión son revelación” ${ }^{\prime 4}$. Según dice, la revelación poética acontece en el interior del sujeto, mientras que la revelación religiosa es una revelación exterior. La revelación poética es una "revelación de sí mismo que el hombre se hace a sí mismo"45, mientras que la revelación religiosa proviene de un poder sobrenatural ajeno al sujeto que "pretende revelarnos un misterio" ${ }^{\prime 4}$. ¿Podemos decir algo de esa experiencia revelatoria?

Paz considera que la insuficiencia del lenguaje nos impulsa a buscar en la poesía la posibilidad de balbucir la experiencia de lo sagrado. ¿Cómo hablar de esta experiencia sacra? $Y$ anota que dicha experiencia no tiene que ser repulsiva, sino revulsiva, es decir, una experiencia que "tiene que echar fuera lo interior y secreto, un mostrar las entrañas [...] una revelación de lo escondido" ${ }^{47}$.

Ahora bien, si según Paz lo escondido se revela, habrá que colegir que el misterio (lo secreto, oculto, aquello difícil de ver y decir) ciertamente se manifiesta -aunque

${ }^{41}$ Paz, Obras completas I: La casa de la presencia, 178.

${ }^{42}$ Ibíd.

${ }^{43}$ En este sentido, es notable el modo como el teólogo Gerhard Ebeling, defensor del primado del vocablo "revelación" como categoría primordialmente teológica, acceda a señalar la posibilidad de un sentido estético del término (véase a Ebeling, Dogmatica della fede cristiana).

${ }^{44} \mathrm{Paz}$, Obras completas I: La casa de la presencia, 178.

${ }^{45}$ Ibíd.

${ }^{46}$ Ibíd.

${ }^{47}$ Ibíd., 181. 
nunca del todo, puesto que es misterio-, pero ello no puede acontecer sin más. La categoría de lo tremendo y fascinante mencionada por Rudolf $\mathrm{Otto}^{48}$, en su célebre obra Lo santo, no es ajena al sentir paciano cuando hay que referirse a la manifestación del misterio. Según el mexicano, la tierra retumba y el tiempo cronológico se detiene para dar cabida al tiempo del mito: “...la tierra se abre, el tiempo se escinde, por la herida o abertura vemos 'el otro lado del ser"” ${ }^{49}$.

Ciertamente la distinción que Paz realiza entre lo divino y lo sagrado queda siempre delineada de modo ambiguo, pero él no deja de resaltar el hecho de que la poesía se presenta como el lenguaje propicio para hablar de la experiencia que el hombre tiene de lo sagrado: “...lo sagrado no es sino la expresión de una disposición divinizante, innata en el hombre" ${ }^{50}$.

Sin embargo, aun cuando existe esta disposición interior del hombre, lo divino no deja de ser inasible para nuestra razón. Por ello, el lenguaje que se usa para referirse a lo divino es siempre impreciso, dubitativo, y de ahí que -para el poeta mexicanotanto el lenguaje místico de la tradición cristiana como el nirvana del budismo se presenten como "nociones negativas y positivas al mismo tiempo, verdaderos 'ideogramas numinosos de lo Otro"' ${ }^{1}$. Ahora bien, si se habla de una disposición interior en el hombre respecto de lo divino, Paz no termina de aceptar que eso que se revela tenga que estar fuera del sujeto:

...la experiencia de lo sagrado no es tanto la revelación de un objeto exterior a nosotros - dios, demonio, presencia ajena- como un abrir nuestro corazón a nuestras entrañas para que brote ese otro escondido. La revelación, en el sentido de un don o gracia que viene del exterior, se transforma en un abrirse del hombre a sí mismo. ${ }^{52}$

Para Paz, la experiencia de la revelación de aquel misterio que nos seduce estremece y sobrepasa puede abordarse de dos maneras:

- La vía del discurso teológico a partir de categorías dogmáticas que pretenden sistematizar un discurso capaz de dar cuenta de nuestra fe y de un constante proceso de interpretación de la experiencia cristiana que exige el resguardo de la ortodoxia.

\footnotetext{
${ }^{48}$ Otto, Lo santo.

${ }^{49}$ Ibíd.

${ }^{50}$ Ibíd., 182.

${ }^{51}$ Paz, Obras completas I: La casa de la presencia, 182.

${ }^{52}$ Ibíd., 182-183.
} 
- $\quad$ La vía poética, que mediante un discurso que no es racional pero que sin llegar a ser irracional no utiliza proposiciones sintéticas para elaborarse, sino que su decir sobre aquel misterio que acontece es también limitado e imperfecto; sin embargo, el carácter simbólico que le es propio, le permite decir algo de eso que se nos presenta como don, toda vez que al decir "esto", la poesía señala y dice "aquello otro".

Ay ¿qué se lleva uno al otro lado? No el mirar, lo aquí

lentamente aprendido, ni nada ocurrido aqui. Nada.

Pero si los dolores. Y también, sobre todo, la pesadumbre,

la larga experiencia del amor: sí

lo puramente indecible.53

La dimensión simbólica que se presenta en la palabra poética hace que la poesía encierre en sus entrañas una fuerza mistagógica que nos conduce a un horizonte infinito en donde el misterio del mundo acontece, emerge. Con todo, la consecuencia común de aquel misterio que se revela es el hecho de sentirnos/sabernos a nosotros mismos finitos, abiertos y, al tiempo, tendientes a la unidad.

Así, al develarnos la naturaleza que nos constituye (finitud), la revelación poética también nos deja en claro el hecho de saber que somos potencia, esto es, que estamos llamados a ser en plenitud, llamados a la comunión con el otro. En otras palabras, cuando en medio de nuestra cotidianidad una luz casi imperceptible nos sale al encuentro y nos disponemos a dejarnos bañar por ella, somos capaces de advertir de modo distinto nuestro mundo y nuestra condición misma de habitantes del mundo; todo se cubre de esa luz y todo se percibe de modo distinto; y cuando esa luz alcanza a iluminar los resquicios de nuestro ser, dilatando nuestra alma y ensanchando nuestra esperanza, nos encontramos ante una revelación.

\section{El carácter mistagógico de la poesía}

Es notable el modo como Octavio Paz defiende las relaciones entre religión y poesía. Sin embargo, en su propuesta sobre la revelación poética advierte cierto distanciamiento entre la revelación propia de la teología y la revelación poética, puntualizando dicha distancia en dos argumentos esenciales:

- En la revelación de la que da cuenta el cristianismo lo que acontece es un evento eminentemente sobrenatural, y por ende, externo al hombre.

${ }^{53}$ Rilke, "Novena elegía", citado por Cuesta Abad y Vega, La novena elegía. Lo decible y lo indecible en Rilke. 
- A diferencia de la revelación poética, cuya experiencia no necesita ser interpretada, en la revelación cristiana apenas acontece la manifestación; esta es arrebatada por un sistema doctrinal para ser correctamente interpretada.

Llegados a este punto habrá que darnos a la tarea de responder, en la medida de nuestras posibilidades, a los dos argumentos pacianos aquí señalados. Para ello es necesario hacer una breve revisión al problema de la revelación del que da cuenta la teología. En efecto, la constitución Dei Filius señala enfáticamente que la revelación es en sí misma un evento eminentemente sobrenatural y que, aun cuando pudiera ser comprendida por la razón, no puede sujetarse a ella, toda vez que quien se revela es Dios mismo ${ }^{54}$. Veamos lo que al respecto señala dicha constitución: "Plugo [a Dios], sin embargo, a su sabiduría y bondad revelarse a sí mismo y los decretos eternos de su voluntad al género humano por otro camino, y este sobrenatural"s5.

No es este el lugar adecuado para hacer una extenuante explicación del contexto en el que surge tal afirmación conciliar; tampoco podemos detenernos en los criterios hermenéuticos con los que hay que acercarse al texto magisterial. Baste ir al centro de lo enunciado por la constitución y detectar que, efectivamente, al hablar de la revelación de Dios se enfatiza en que se trata de un evento sobrenatural, más no por ello externo al hombre.

$\mathrm{Al}$ respecto señala Heinrich Fries que, cuando el Concilio Vaticano I utiliza este término, lo hace para remarcar el carácter de los bienes divinos de los cuales somos herederos, bienes que en efecto superan nuestras capacidades humanas. Sin embargo, al decir de este autor, el uso que la Dei Filius hace del término sobrenatural termina siendo ambiguo; y de manera contraria, el Concilio Vaticano II hablará con mayor claridad de la revelación como acontecimiento que "se realiza con hechos y palabras, intrínsecamente conexos entre sî" ${ }^{\prime 56}$.

Sin mayores contextualizaciones dogmáticas -que no eran del interés del poeta, ni él tenía por qué conocerlas-, Octavio Paz conoció dicho modelo doctrinal que deja la revelación en un contexto aparentemente extrahumano. Este es un punto de conflicto para él: el hecho de que la revelación religiosa proviene de un poder sobrenatural ajeno al sujeto y pretende revelarnos un misterio ajeno a nosotros ${ }^{57}$.

\footnotetext{
${ }^{54}$ Concilio Vaticano I, “Costituzione dogmática Dei Filius (1870)”.

${ }^{55}$ Citado por Dezinger y Hünermann, El magisterio de la Iglesia. Enchiridion Symbolorum Definitionum, 3004.

${ }^{56}$ Fries, Teología fundamental, 398.

${ }^{57}$ Véase a Paz, El arco y la lira.
} 
A nuestro entender, la postura del poeta Paz obedece a una concepción cristiana decimonónica, que se fermenta y concentra en un ambiente clerical, como el del contexto mexicano, al menos hasta las postrimerías del siglo pasado.

A simple vista resulta más o menos evidente que dichos modelos no pueden tener conciliación aparente. Para Octavio Paz, la revelación poética atañe únicamente al sujeto, no puede venir de fuera suyo, ni acontecer en lugar alguno que no sea en su interior. Sin embargo, dada nuestra intención de resaltar el carácter mistagógico de la poesía, y por ello mismo el que sea mediación propicia para aproximarnos a la revelación del misterio de Dios, es necesario ir más allá de lo previsto por el Paz. Y al dar este paso estamos conscientes de que ya no estamos siguiendo la postura paciana, de que no le haremos decir al poeta mexicano lo que no quiso decir.

Nuestra pretensión es ya una mera aventura del pensamiento que pretende echar mano de las posibilidades del lenguaje poético. A este fin necesitamos ahora dar otro tipo de salto, y así pasar de la revisión conciliar acontecida a finales del siglo XIX al gran acontecimiento eclesial que tuvo lugar en la segunda mitad del siglo XX, el Concilio Vaticano II. En dicho evento, la constitución dogmática Dei Verbum, sobre la divina revelación, da un giro radical respecto del precedente acuñado por la $D e i$ Filius. Veamos un punto central de dicho documento:

Quiso Dios, con su bondad y sabiduría, revelarse a sí mismo y manifestar el misterio de su voluntad (Ef 1,9): por Cristo, la Palabra hecha carne, y con el Espíritu Santo, pueden los hombres, llegar hasta el Padre y participar de la naturaleza divina (Ef 2,28; 2 P 1,4). En esta revelación, Dios invisible (Col 1,15; 1Tm 1,17), movido de amor, habla a los hombres como amigos (Ex 33,11; Jn 15,14-15), trata con ellos (Ba 3,38) para invitarlos y recibirlos en su compañía. ${ }^{58}$

La Dei Verbum está tomando como punto directo de partida el antecedente inmediato que había quedado consagrado en la Dei Filius. Con ello pone en claro que, cuando nos referimos a la revelación, estamos hablando de un acontecimiento que tiene su origen en la mismísima iniciativa divina. Así se enfatiza en que se trata de un acontecimiento que nos viene dado. Y aquí radica ya una peculiaridad resaltada por la Dei Verbum: que la revelación es un acto de donación amorosa.

Ahora bien, el giro radical de esta constitución inicia al omitir el carácter sobrenatural mencionado por la Dei Filius. Con ello no pretende aminorar el carácter trascendental del acontecimiento revelatorio: antes bien, al continuar señalando que se trata de un acto que tiene su origen en la voluntad y sabiduría divinas, la condición

\footnotetext{
${ }^{58}$ Concilio Vaticano II, “Constitución dogmática Dei Verbum sobre la divina revelación” 2.
} 
sobrenatural queda implícita. Los padres conciliares están tratando de dejar en claro, precisamente, como parte de ese mismo plan de Dios, que lo divino ha querido hacerse accesible a los hombres por medio de Cristo, y así, con él y por él, nuestra condición humana (finita y débil) puede ser divinizada; es decir, que la condición humana puede participar (en Cristo y en unidad con el Espíritu) de la vida divina.

A todas luces, el texto nos deja en claro que la revelación de Dios no es un acontecimiento meramente sobrenatural. Tampoco se trata de un acto externo o ajeno al hombre, sino es un acontecimiento donante que surge de la voluntad divina. El texto conciliar enfatiza en el equilibrio entre lo trascendente y lo inmanente: Dios que visita a su pueblo ahí donde este habita, en el mundo, en la historia. Dios viene al hombre y así lo acoge, lo eleva, lo hace partícipe de su propia vida.

Consideremos ahora otro señalamiento acuñado por la Dei Verbum:

El plan de la revelación se realiza por obras y palabras intrínsecamente ligadas; las obras que Dios realiza en la historia de la salvación manifiestan y confirman la doctrina y la realidad que las palabras significan; a su vez, las palabras proclaman las obras y explicitan su misterio. La verdad profunda de Dios y de la salvación del hombre que transmite dicha revelación, resplandece en Cristo, mediador y plenitud de toda revelación. ${ }^{59}$

De este modo, la revelación divina presentada por la Dei Verbum no sienta las bases del acontecimiento revelatorio a partir de un corpus doctrinal ${ }^{60}$; es decir, la revelación no se presenta -ni debe ser entendida- únicamente como una serie de verdades de $\mathrm{f}^{61}$ contenidas en el texto sagrado y salvaguardadas por el magisterio eclesiástico. Antes bien, lo que acontece en la revelación es Dios mismo que viene al mundo: así, la revelación no es otra cosa que la autocomunicación de $\operatorname{Dios}^{62}$ en la historia de la humanidad ${ }^{63}$.

En consecuencia, es más que un hecho que al hablar de la revelación desde el ámbito teológico no estamos haciendo referencia a un mero acto sobrenatural, al modo como lo entendía el poeta Octavio Paz (algo externo al hombre, que se presenta como una imposición); más bien se trata de un acontecimiento salutífero que se incardina en la historia; acontecimiento que echa mano de las mediaciones humanas para expresarse.

\footnotetext{
${ }^{59}$ Concilio Vaticano II, “Constitución dogmática Dei Verbum sobre la divina revelación” 2.

${ }^{60} \mathrm{Al}$ respecto véase a Fries, Teología fundamental.

${ }^{61}$ Concilio Vaticano II, "Constitución dogmática Dei Verbum sobre la divina revelación” 2 y 17.

${ }^{62}$ Ibíd. 6.

${ }^{63}$ Ibíd. 2 y 3.
} 
En este sentido, lo que debe ser comprendido por el ser humano en la revelación no es la comunicación de un conocimiento más elevado, sino el develamiento del misterio (sacramentum). Por ello, las mediaciones históricas y lingüísticas son la parte operativa ${ }^{64}$ de la misma revelación. Sobre este sentido operativo, el teólogo Hans Waldenfels señala que la revelación se puede entender como un concepto perceptivo; y si podemos percibirle, es menester decir que se trata de un concepto estético: “...las percepciones se producen de diversos modos en espacio y tiempo concreto con todos los sentidos que están a disposición del hombre"6s.

Por eso, si la revelación debe ser perceptible y experimentable, podemos hablar de una estética presente en la revelación. ¿Qué significa para Waldenfels dicha dimensión estética? Necesariamente, una actitud por parte del sujeto ante la percepción de la revelación: no se trata de una experiencia esteticista, sino de una experiencia que implica lo actitudinal. No se es únicamente entender cómo ocurre la revelación, sino compenetrarnos de lo que dicho acontecimiento revela: el misterio.

En este sentido, la concepción estética de la revelación de Waldenfels alude a una forma de ver y actuar en y desde el mundo a la luz del misterio que se nos devela. A este respecto, nuestro planteamiento no implica que la revelación divina deba ser entendida como mero ejercicio de interpretación; por el contrario, aquí queremos decir que, precisamente, la revelación divina implica una experiencia de recepción/ percepción que afecta al sujeto, y que dicha manifestación puede llegar a ser inteligible gracias a su capacidad simbólica.

Es así como la palabra escrita da pie a una Palabra más vasta. La dimensión simbólica del lenguaje media el acontecer del misterio que se nos revela como don y Palabra; por ello, si el lenguaje es el medio por el cual el hombre se expresa y da nombre a la realidad, entonces existe en él una capacidad creativa/creadora y, por ende, el hombre, al nombrar la realidad, también es un creador ${ }^{66}$.

A la luz de lo que aquí se ha expuesto podemos hacer énfasis en la relación que existe entre teología y poesía. Como hemos señalado, si la revelación de la que da cuenta la teología tiene como centro el develamiento de un misterio que -en cuanto don- es susceptible de ser comprendido por el hombre, y si el papel de la revelación poética radica en develar lo que constituye lo propio de nuestra naturaleza (nuestro

\footnotetext{
${ }^{64}$ Por "operativa" queremos decir los medios humanos por los cuales es posible percibir la revelación.

${ }^{65}$ Waldenfels, Hans. Teología fundamental contextual, 209.

${ }^{66} \mathrm{Al}$ respecto véase a Fries, Teología fundamental.
} 
ser finito, débil, abierto) ${ }^{67}$, y el esfuerzo por narrar la experiencia que el hombre tiene de eso que le preocupa en ultimidad (lo que Paul Tillich ha llamado "the ultimate concern”), estamos en posibilidad de defender una relación entre lo teológico y lo poético a partir de la dimensión simbólica que radica en ambos lenguajes.

En este contexto, las contribuciones del teólogo compostelano Andrés Torres Queiruga a la teología de la revelación no pueden ser pasadas por alto. Ya desde la temprana publicación de Constitución y evolución del dogma, fruto de su tesis doctoral, Torres Queiruga se encontró con la necesidad de abordar de lleno el asunto de la revelación como problema teológico de primer orden; en aquel texto preconizaba lo que profundizaría más adelante en su obra Repensar la revelación. Dice este autor en Constitución y evolución del dogma:

La palabra revelada [...] no le habla al hombre de algo extraño a sí mismo, sino que, por el contrario, trata de hacerle tomar conciencia de su ser más auténtico, de iluminarlo sobre la concreta situación en que se realiza su historia [...] embarcado en su dinamismo [de la palabra], el hombre no navega hacia extrańos mares, sino hacia el encuentro consigo mismo. ${ }^{68}$

Nuevamente podemos constatar que la irrupción de la revelación de la que da cuenta el cristianismo no tiene que ver tanto con un movimiento meramente externo al sujeto, sino está en íntima relación con lo que le es propio, la conciencia de sí mismo. Este tipo de aproximación a la revelación -más prístina y cercana a la realidad humana- estaría resolviendo el problema de eso que tanto inquietaba a Octavio Paz: la concepción de una revelación entendida como un acontecer meramente externo al sujeto y el hecho de ser susceptible a una interpretación doctrinal.

Con todo, sin pretender armonizar las visiones de estos autores, lo que aquí interesa resaltar es la posibilidad de una comprensión de la revelación como experiencia de apertura del hombre al misterio que le constituye a sí mismo y, también, como apertura al misterio de lo divino como fundamento de la realidad ${ }^{69}$.

\footnotetext{
${ }^{67}$ En efecto, Octavio Paz tiene razón al señalar que la revelación poética nos revela lo propio de nuestra condición humana, esto es, nuestro ser abierto, débil, finito. En ello coinciden las posturas, tanto de P. Tillich, como de otros teólogos (K. Rahner, E. Jüngel, H. Fries); sin embargo, la experiencia que implica la toma de conciencia de nuestra finitud no termina solo con ese sabernos expuestos; antes bien, ello es apenas el detonante de una acción consecuente, preguntarnos por lo infinito a partir de nuestra propia finitud.

${ }^{68}$ Torres Queiruga, Constitución y evolución del dogma. La teoría de Amor Ruibal y su aportación, 225.

${ }^{69}$ Cercana es la postura del teólogo Adolphe Gesché, al mencionar una doble dimensión del misterio; es decir, así como Dios se presenta como misterio para el hombre, en el hombre hay también algo enigmático que se presenta como misterio de lo humano ante lo divino. $\mathrm{Al}$ respecto dice el autor: “...yo solo me comprendo si Dios sigue siendo parcialmente un enigma para mí; pero yo no me
} 
En su obra La revelación de Dios en la realización del hombre, y su edición revisada y aumentada, Recuperar la revelación, Torres Queiruga presenta la revelación ayudado de la figura mayéutica. Con ello quiere alejarse de esas posturas teológicas que conciban la revelación como acción divina, tan radical en su aspecto trascendente que deje de lado lo inmanente; es decir, se opta por un modelo que ayude a repensar la revelación como anuncio dinámico:

...anuncio [que] empuja hacia delante: hacia el crecimiento y la realización del nuevo ser que se adquiere en la historia [...una] llamada a reconocer, acoger y realizar el propio ser; el más real y verdaderamente propio, aunque no como clausurado en sí mismo, sino en cuanto se lo descubre como fundado, habitado, agraciado y promocionado por Dios. ${ }^{70}$

Así entendida, la revelación de Dios no puede estar desvinculada de la historia; tampoco es un acontecer ajeno o impuesto al sujeto. Por el contrario, la revelación de la que da cuenta el profesor gallego es "acogida en la subjetividad humana, intrínsecamente histórica, [la cual] acontece necesariamente en el cambio y dramatismo inherentes a toda historia viva” ${ }^{11}$. La propuesta del teólogo compostelano señala que la revelación de Dios acontece en la historia, cuya dinámica operativa pone en relación tanto al objeto como al sujeto de la revelación ${ }^{72}$; enfatiza también en que la revelación divina opera como develación del misterio del sujeto como conciencia de sí, y como develación del misterio de Dios en cuanto fundamento de lo real.

En buena medida, la propuesta de Torres Queiruga estaría apoyando nuestro argumento de ver una función mistagógica en la poesía, toda vez que la revelación divina implica una "experiencia de develamiento que se expresa a través de un lenguaje peculiar, simbólico y creativo, en un proceso afín al de la creación artística" ${ }^{73}$. La revelación divina se entiende entonces como proceso que involucra la manifestación de lo que nos trasciende, pero también la escucha y la acción por parte del sujeto. Gracias

comprendo tampoco si es que no soy también, en parte, un enigma para Dios” (Gesché, El sentido [Dios para pensar VII] 193).

${ }^{70}$ Torres Queiruga, Repensar la revelación. La revelación divina en la realización humana, 134-135.

${ }^{71}$ Ibíd., 202.

${ }^{72}$ Este relación objetivo-subjetiva ha sido enfatizada por Paul Tillich, al decir que "la revelación es siempre un acontecimiento subjetivo y un acontecimiento objetivo en estricta interdependencia. Alguien se siente embargado por la manifestación del misterio; este es el lado subjetivo del acontecimiento. Algo ocurre a través de lo cual el misterio de la revelación embarga a alguien; este es el lado objetivo del acontecimiento [...] El suceso objetivo y la recepción subjetiva pertenecen al acontecimiento total de la revelación" (Tillich, Teología sistemática. Vol. I: La razón y la revelación. El ser y Dios, 149).

${ }^{73}$ Torres Queiruga, Repensar la revelación. La revelación divina en la realización humana, 236. 
a ello, el acto revelador se puede narrar como una relación con la trascendencia, pero también con la humanidad.

En este sentido, la afinidad entre el modo como opera la revelación de la que da cuenta la teología y el modo operante de la revelación poética del que ya nos hemos ocupado en este trabajo, nos permite resaltar el papel mistagógico de la poesía. Así, la revelación poética adquiere elementos teologales. Aquella realidad última que se nos manifiesta disipa las nubes de nuestros ojos, permitiéndonos ver el mundo con una mirada distinta, diáfana (fides).

Se trata de una fe que nos invita a hacer de este mundo un lugar más acogedor donde habitar (spes), haciendo posible que bajo la dinámica creativa del eros busquemos propiciar encuentros fraternos y reconciliadores (caritas). En esta dinámica poético-teologal la poiesis poética tiene implicaciones con la poiesis teológica, cuyos efectos no son meramente estéticos sino existenciales y éticos: estamos llamados a ser creadores de nuevos rincones propicios para el ágape.

\section{A modo de conclusión: "las peras del olmo"}

Llegados a este punto, tras nuestra pretensión de señalar el carácter mistagógico de la poesía y su mediación propicia para aproximarnos a la revelación del misterio de lo divino, seguramente el crítico literario respondería que Octavio Paz nunca pretendió semejante cosa. Por su parte, el teólogo dogmático calificaría nuestra postura como un atrevimiento teológico.

Frente al crítico literario habrá que responder que nuestra pretensión no ha sido, en absoluto, intentar "hacer decir" a don Octavio cosas que ciertamente no dijo. No obstante, sus obras dejan ver que la inquietud paciana merodea los rincones de lo divino, aguardando siempre la manifestación de la otredad a la que no identifica con un credo específico y, sin embargo, le conmueve hasta el llanto ${ }^{74}$.

Por su parte, al teólogo debemos responderle que nuestra intención no es hablar de la poesía como la revelación divina en sí misma, pero sí como medio, como un lenguaje propicio para murmurar lo inefable del misterio divino, como una entidad propia cuyo discurso es, no solo legítimo y válido, sino necesario.

En consecuencia, nuestra propuesta incursiona en la ladera de la teología fundamental, toda vez que pretende hablar de los criterios de posibilidad que existen

\footnotetext{
${ }^{74}$ Así parece constatarlo sus mismas palabras: “...un día en Goa, en el centro de una civilización que no era la mía, entré a la vieja catedral. Celebraba la misa un sacerdote portugués, en portugués. La escuché con fervor. Lloré. No sé todavía si descubrí algo [...] pero sentí la presencia de eso que han dado en llamar la otredad" (Paz, Obras completas VIII, 664: "Alguien me deletrea").
} 
para replantearnos el asunto de la revelación de Dios más allá de los linderos de la teología especulativa, ahí donde acontece la vida ordinaria, porque es ahí, en medio de lo profano, donde Dios se nos manifiesta. ¿¿Será acaso que le estamos pidiendo peras al olmo? En efecto, nada puede ilustrar mejor este ejercicio que el título del bello libro de don Octavio Paz, Las peras del olmo. Tanto el teólogo como el poeta deben plantar olmos, de cuyas ramas broten apetitosas peras.

\section{Referencias}

Angelus Silesius. El peregrino querúbico. Edición y traducción de Lluis Duch. Madrid: Siruela, 2005.

Concilio Vaticano I. "Costituzione dogmática Dei Filius (1870)". Vatican, http:// www.vatican.va/archive/hist councils/i-vatican-council/documents/vat-i const 18700424 dei-filius it.html (consultado el 9 de mayo de 2019).

Concilio Vaticano II. "Constitución dogmática Dei Verbum sobre la divina revelación (1965)”. Vatican, http://www.vatican.va/archive/hist councils/ii vatican council/documents/vat-ii const 19651118 dei-verbum sp.html (consultado el 10 mayo de 2019).

Cuesta Abad, José Manuel y Amador Vega. La novena elegía. Lo decible y lo indecible en Rilke. Madrid: Siruela, 2018.

Dezinger, Heinrich, y Peter Hünermann. El magisterio de la Iglesia. Enchiridion Symbolorum Definitionum (2. a ed. corregida). Barcelona: Herder, 2000.

Ebeling Gerhard. Dogmatica della fede cristiana. Genova: Marietti, 1990.

Fries, Heinrich. Teología fundamental. Barcelona: Herder, 1987.

Gesché, Adolphe. El sentido (Dios para pensar VII). Salamanca: Sígueme, 2004.

Otto, Rudolf. Lo santo. Prólogo de Manuel Fraijó Nieto. Madrid: Alianza, 2016.

Paz, Octavio. El arco y la lira. México: Fondo de Cultura Económica, 2010. . Las peras del olmo. México: Universidad Nacional Autónoma de México, UNAM, 1957.

. Los hijos del limo. Barcelona: Seix Barral, 1990.

. Obras completas. Vol. I: La casa de la presencia. Barcelona: Galaxia GutenbergCírculo de Lectores, 1999.

. Obras completas. Vol. VII: Obra poética. Barcelona: Galaxia Gutenberg-Círculo de Lectores, 2004. 
. Obras completas. Vol. VIII: Miscelánea. Barcelona: Galaxia Gutenberg-Círculo de Lectores, 2005.

Rilke, Rainer Maria. "Novena elegía”. En Elegías de diuno, por R. M. Rilke. Barcelona: Lumen, 1980.

Ruy Sánchez, Alberto. Una introducción a Octavio Paz. México: Joaquín Mortiz, 1990.

Tillich, Paul. Dogmática (Lecciones de Dresde 1925-1927). Madrid: Trotta, 2013. . Main Works. Vol. 6. Theological Writings. Berlin-New York: Walter de Gruyter, 1992.

. "Religious Symbols and Our Knowledge of God". The Christian Scholar 38/3 (1955): 189-197.

- Teología sistemática. Vol. I: La razón y la revelación. El ser y Dios. Salamanca: Sígueme, 1981.

. "Theology and Symbolism". En Religious Symbolism, editado por F. Ernest, 107-116. New York (NY): The Institute for Religious and Social Studies, 1969.

Torres Queiruga, Andrés. Constitución y evolución del dogma. La teoría de Amor Ruibal y su aportación. Madrid: Marova, 1977.

. Repensar la revelación. La revelación divina en la realización humana. Madrid: Trotta, 2008.

Waldenfels, Hans. Teología fundamental contextual. Salamanca: Sígueme, 1994. 